Article

\title{
Study Informing Policy on Chinese Ancient Town Tourism Based on a Tourist Satisfaction Survey: A Case Study in the City of Chengdu
}

\author{
Yan Liu ${ }^{1}$, Shaowei Ning ${ }^{1,2, *}$, Isao Oyama ${ }^{3}$ and $\mathrm{Li} \mathrm{Li}^{4}$ \\ 1 Division of Environmental Engineering, University of Yamanashi, Koufu 400-8510, Japan; \\ g14de005@yamanashi.ac.jp \\ 2 School of Civil Engineering, Hefei University of Technology, Hefei 230009, China \\ 3 Graduate Faculty of Interdisciplinary Research, University of Yamanashi, Kofu 400-8510, Japan; \\ ooyama@yamanashi.ac.jp \\ 4 School of Transportation and Logistics, Southwest Jiaotong University, Chengdu 610031, China; \\ speciallili@home.swjtu.edu.cn \\ * Correspondence: ning@hfut.edu.cn; Tel.: +86-551-6290-3357
}

Received: 6 April 2017; Accepted: 18 June 2017; Published: 22 June 2017

\begin{abstract}
This paper discusses the customer satisfaction of tourists in Chengdu and proposes corresponding countermeasures for tourism development of Chinese traditional areas. The Customer Satisfaction (CS) analysis method is applied to draw the following conclusions: visitors are satisfied with the historical landscapes-such as traditional historical streets, historical buildings as well as waterside landscapes, natural landscapes and infrastructures-which are the key points in the future development of tourism, and are essential to maintain. On the other hand, priority should be given to improving the current shortfalls, namely the protection and improvement of traditional culture, such as the spirit and experience of local life, as well as the experience of traditional culture. In this regard, it is recommended that direct measures are taken, such as preventing the loss of local residents and calling for a return of indigenous people to their hometowns to maintain local traditional cultures. What is fundamentally necessary is to help local residents understand tourists' desperate demands for local traditional cultural resources. In parallel, it will be important to inspire local residents to value and celebrate their traditional cultural lives and resources.
\end{abstract}

Keywords: satisfaction evaluation; traditional historical streets; traditional culture; customer satisfaction analysis method

\section{Introduction}

Due to developments in economic reform, paired with opening up to foreign trade, China's domestic economy is experiencing high-speed growth, and living standards have been improved considerably [1]. In addition, the number of tourists visiting China each year is growing, and understanding of the economic impact of tourism has changed substantially [2]. Correspondingly, increasing attention is being paid by government and researchers to the development of tourism in order to promote economic growth. Research suggests that tourism is the most dynamic emerging industry in China's tertiary sector and has a high potential to boost the economy [3,4]. In the city of Chengdu, for example, the number of tourists, and accompanying monetary income, showed an obvious upward trend from 2001 to 2015, especially after 2009. By the end of 2015, the number of visitors to Chengdu had reached 189 million, with tourism revenue as high as 31.88 billion US dollars.

Although there has been some development in the tourism industry, significant problems remain, including the deterioration of the natural environment, the disappearance of a sense of 'glamor' in 
traditional areas, the loss of residents due to overdevelopment, and the resulting, loss of traditional culture [5-8]. Traditional areas in China have rich natural, cultural and historical landscapes, which have been built up over time by generations of local residents in their daily lives [9]. These landscapes have both a historical-cultural value and a high economic value [10]. However, due to an emphasis on the economic benefits of the tourism development model, there are great challenges to the sustainable development of traditional tourism destinations as they are transformed from traditional resources to tourism resources.

For instance, Wulingyuan, located in the north-west of Hubei province, with its striking natural landscape, was recognized by UNESCO as world heritage site in 1992. However, with the development of tourism resources, crudely-made artificial structures led to the destruction of the natural environment, and thus resulted in a warning from UNESCO in 2013 [11].

In Suzhou, the ancient capital of Jiangsu, the government sold some of the traditional buildings and used non-governmental funds for repair and development, including funding from private enterprises with foreign capital. This is illegal according to municipal law. The government, therefore, approached the repair and development of traditional buildings recklessly. The concept of the Suzhou municipal government, according to the formulation of the law, is forbidden. Nevertheless, the commercialization of cultural heritage is widespread in the country [12].

With the increasing diversity of urban life in China, natural landscapes, traditional customs and food are increasingly compromised. As such, in-depth research into the development of traditional tourism resources could resolve the conflict between sustainability and economic growth.

This study investigates tourists' attitudes towards travel in Chengdu and neighboring towns, in order to establish which elements of their experience they find satisfactory or unsatisfactory. Through this, the study establishes and explores the favorable as well as inferior resources in the area, so as to propose a methodology for sustaining traditional sightseeing tourism destinations. It is hoped that this proposal will contribute to the study of sustainable tourism in the future.

\section{Previous Research}

Before 1980, research on ancient towns in China had hardly begun, and studies were few, scattered and unsystematic. Since 1990, the popularity of tourism activities and the development of ancient villages and towns has gradually attracted the attention of scholars, yet most of this research is related merely to case studies, survey reports, and so on. The main focus areas of research on ancient towns since the 1990s include the development and preservation of ancient towns [13-15], the developmental mode of ancient towns [16] and problems faced in town development [17]. None of this research is aimed at the study of tourists' experience and attitude; rather, the research is aimed only at qualitative analysis, such as paying attention to the characteristics of ancient towns, residents' lack of awareness and the transformation of buildings.

In terms of research on tourists' experience in traditional tourist areas, Wang takes Suzhou country as a case study to investigate visitors' preferences and behaviors. He points out that most tourists favor types of rural tourism including the villages' ecological environments- the Forest Parks and ancient villages-while the popularity of new rural landscapes and the aquaculture industry is relatively low. However, tourists' satisfaction factor is not included in the research [18]. Wang conducts an analysis of the relationship between tourist satisfaction and tourist tendencies, only concluding that the perception of tourism and tourist behavior has some relevance [19]. Long, on the other hand, investigates the satisfaction of tourists visiting Fenghuang Ancient City, simply pointing out that tourists are satisfied with the experience of ancient and cultural landscapes, but not with emergency services, healthcare facilities, opportunities for shopping and the like. There is no in-depth analysis of specific content related to satisfaction [20]. Wang also analyzes the commentary material and interpretation methods provided as context at natural disaster sites in Sichuan province and conducts research on tourists' awareness of this information. He points out that the commentary at these sites meets tourists' needs 
to a certain extent, but the explanations, commentary and interpretation are neither abundant enough nor are they specific and vivid [21,22].

Liu takes Chengdu, Sichuan and neighboring towns as case studies. Using the tree method, he examines the experience of tourists and focuses on the influence of comprehensive satisfaction factors [23]. He points out that, while factors such as historical anecdotes and the lifestyle of local residents have a significant impact on tourist satisfaction, discontent with the traditional street landscape, historical buildings and traditional landscapes will reduce tourists' satisfaction. Liu's use of the tree method in this research leads to a disjointed and scattered analysis, which does not completely account for influences on satisfaction factors. In order to build a policy for the long-term development of tourism in China, it is necessary to carry out a more comprehensive analysis, which includes factors that influence the degree of tourist satisfaction. The results will point to which factors should be prioritized in tourism development policy and which require more research and development to enhance tourist satisfaction. Thus, long-term, effective and sustainable development policies for tourist resorts should be based on research that provides clear data on tourist satisfaction for a variety of factors.

Based on this background, it is clear that there is a lack of basic research on tourist experience in China and, in addition, little to no quantitative analysis informing policy decisions.

\section{Survey Site Outline}

Chengdu's history spans over 2300 years and it is rich in cultural heritage. It is one of the 20 largest cities in China and is also the center of Sichuan province and the center of Southwest China. Chengdu was designated a national historical and cultural city in 1982. In 2000, as a stronghold of western development, Chengdu was active in economic growth. There are many historical buildings in Chengdu that are identified as world cultural heritage sites, including the Temple of Marquis (Kongming Zhuge's temple, the holy land of the Three Kingdoms), Du Fu's Thatched Cottage (Du Fu's former residence), Wenshu Monastery (the ancient temple built in the Northern and Southern Dynasties), Kuan Alley and Zhai Alley (the ancient streets built at the end of the Qing Dynasty) and Huanglong Valley (an ancient town in the southern suburbs of Shuangliu County). In addition, there are many world cultural heritage sites and natural heritage sites in Sichuan province, such as Jiuzhaigou valley, Huanglong scenic area, the Mount Emei, Leshan Giant Buddha and other tourist destinations. Sichuan province is both a precedent and a model to develop tourism resources as an industry [24].

The atmosphere that is full of personality and traditional culture has been preserved through architecture-in traditional historical buildings and streets-as well as through daily life such as worship and festival activities, in addition to morning markets. In the future, as an important city in Southwest China, Chengdu will potentially become a model city for the protection of traditional resources and the smooth development of tourism. Therefore, this study undertakes an analysis of the following scenic spots: Wide and Narrow Alley, Jinli and Wenshu Monastery within Chengdu city, Huanglongxi ancient town and Anren ancient town outside Chengdu. The selection of these sites takes into account that tourists who travel to ancient towns in Chengdu tend to travel to nearby ancient towns in addition to sites located in the city. Additional reasons for the selection of these specific case studies are as follows:

(1) The sites are all established tourist destinations.

(2) The sites' traditional resources have already been developed into tourism resources.

(3) Each of the sites has historical, artistic and scientific value.

(4) All of the sites reflect the social heritage and social life of all ages of inhabitants.

(5) All of the sites once flourished as a place of residence. 


\section{Questionnaire Analysis}

\subsection{Survey Summary}

From mid to end March 2015, we conducted a field visit to Chengdu and its surrounding towns and conducted a survey via questionnaire. The questionnaire mainly comprised questions that aimed to establish the basic characteristics of tourists and their satisfaction with tourism projects. During this time, on-site interviews via intercept surveys were conducted for each site.

\subsection{Tourist Characteristics}

The characteristics of the visitors are shown in Table 1. In each region, there were 110 respondents to the survey, with a total number of 550 people. By gender, there were 281 male respondents, accounting for $51 \%$, while the number of female respondents was 269 , accounting for $49 \%$, with no obvious deviation in comparison. By age composition, the largest grouping of people was young, between 20 and 30 years old, accounting for $59 \%$, while the remaining age groups counted for below $15 \%$. The ratio of middle-aged and elderly people in the interception questionnaire is not reflective of the tourists' demographics because many middle-aged and elderly people refused to be surveyed. The ratio of younger people and students was fairly high because they were particularly cooperative. According to the category of occupation, students accounted for $47 \%$, staff for $38 \%$ and retirees for $5 \%$. About $90 \%$ of tourists chose day trips; by contrast, the percentage of those that elected to stay for a longer period of time in accommodation remained at only around $10 \%$. In relation to the recommendation of the tourist site, about half of the people had taken the suggestion of family and friends, while the other half had identified the trip out of their own interest. As for the relationships between tourists, the largest proportion was friends, followed by family and relatives, individuals and then lovers. First-time visitors accounted for $44 \%$, and return visitors accounted for about $56 \%$, which is relatively high.

Table 1. Tourist Characteristics.

\begin{tabular}{cccc}
\hline Project & \multicolumn{2}{c}{ Number of People } & Proportion \\
\hline \multirow{2}{*}{ Gender } & Male & 281 & $51 \%$ \\
& Female & 269 & $49 \%$ \\
\hline \multirow{4}{*}{ Age } & $\leq 19$ & 82 & $15 \%$ \\
& $20-30$ & 324 & $59 \%$ \\
& $31-40$ & 75 & $14 \%$ \\
& $41-50$ & 35 & $6 \%$ \\
& $51-60$ & 12 & $2 \%$ \\
& $60-70$ & 22 & $4 \%$ \\
& $\geq 71$ & 0 & $0 \%$ \\
\hline \multirow{2}{*}{ Occupation } & Staff member & 138 & $25 \%$ \\
& Civil servant & 23 & $4 \%$ \\
& Student & 257 & $47 \%$ \\
& Individual household & 48 & $9 \%$ \\
& Retired & 25 & $5 \%$ \\
& Other & 59 & $11 \%$ \\
\hline \multirow{2}{*}{ Residence } & City & 389 & $71 \%$ \\
& Rural & 161 & $29 \%$ \\
\hline \multirow{2}{*}{ Accommodation } & Day trip & 489 & $89 \%$ \\
& Accommodation & 59 & $11 \%$ \\
\hline \multirow{2}{*}{} & & &
\end{tabular}


Table 1. Cont.

\begin{tabular}{cccc}
\hline Project & \multicolumn{2}{c}{ Number of People } & Proportion \\
\hline \multirow{3}{*}{ Recommendation of Site } & Individual & 197 & $36 \%$ \\
& Family and friends & 264 & $48 \%$ \\
& Tour group & 26 & $5 \%$ \\
& Other & 63 & $11 \%$ \\
\hline \multirow{2}{*}{ Tour Group } & Individual & 82 & $15 \%$ \\
& Couples & 73 & $13 \%$ \\
& Friends & 262 & $48 \%$ \\
& Family & 91 & $17 \%$ \\
& Other & 41 & $7 \%$ \\
\hline \multirow{2}{*}{ Visiting Times } & First time & 240 & $44 \%$ \\
& More than twice & 309 & $56 \%$ \\
\hline
\end{tabular}

\section{Satisfaction of Tourist Destinations}

Research through "Customer Satisfaction" (CS) is conducted in many research fields, based on a diversity of research objects, researchers, different exposition perspectives and depth. The degree of customer satisfaction is a numerical index for evaluating how customer's expectations of company products matched their experience. Based on this index, companies are able to develop products and services in order to better meet customer needs and thereby increase their revenue by selling additional products to existing customers as well as those who are attracted by recommendations. This concept can be applied in the field of tourism: if tourists are satisfied, they are likely to return and or recommend the site to others. Satisfactory experiences at tourist sites are thus linked to an awareness of the area as well as potential economic revenue.

Yuksel \& Yuksel $[21,25]$ establish three criteria for judging visitor satisfaction:

(1) destination characteristics: climate, culture, natural environment, and the like.

(2) functional elements: price, tourism resources, accommodation, catering facilities, and the like.

(3) psychological elements: local residents' hospitality, peace of mind, atmosphere, and the like.

While these criteria have been a starting point for this research, prior surveys and on-site investigation prompted slightly different characteristics. Twenty-six elements of tourist experience were identified in order to determine customer satisfaction in the sites in and around Chengdu city. These 26 elements can be divided into five categories: landscape (historical and natural), culture (living, historical and experiential), food and shopping, recuperation and infrastructure. Items (Q1-q26) mean meeting the structural system, which is shown in Table 2, where " $\bullet$ " signifies traditional resources in tourist resorts; " $\square$ " signifies infrastructures and " $\times$ " signifies resources which are unrelated to tourist resorts.

To evaluate the 26 elements, a five-segment rating system is adopted:

$$
\begin{aligned}
& \text { Satisfaction }=5 \text { points } \\
& \text { Fair Satisfaction }=4 \text { points } \\
& \text { Ambiguous }=3 \text { points } \\
& \text { Slight Dissatisfaction }=2 \text { points } \\
& \text { Dissatisfaction }=1 \text { points }
\end{aligned}
$$

After analysis of the results, the answer to "Satisfaction" and "Fair Satisfaction" is "good", the answer of "Ambiguous" is "ordinary", and that of "Slight Dissatisfaction" and "Dissatisfaction" is "bad". The percentage of tourism elements that were rated as either satisfactory or fairly satisfactory is shown in Table 2.

From Table 2, we can see that 12 tourism elements are rated favorably (more than $50 \%$ ), accounting for about half of the overall factors. The following elements were rated as satisfactory, reaching $70 \%$ : 
- $\quad$ Q23. Street Comfort (79.3\%)

- $\quad$ Q21. Street Cleanliness (73.9\%)

- $\quad$ Q8. Traditional Street Landscape (Overall Atmosphere) (71.6\%)

- Q13. Enjoyment of Traditional Delicacies (70.1\%).

In second place-more than $60 \%$-are as follows:

- $\quad$ Q22. Bathroom Cleanliness (68.6\%)

- $\quad$ Q17. Leisure and Rest (68.1\%)

- $\quad$ Q7. Historical Buildings (67.9\%)

- $\quad$ Q24. Enjoyment of Rest Stops (65.9\%)

- Q19. Reunion of Family and Friends (63.3\%)

- Q10. Green Vegetative Landscapes (62\%).

The last section of elements which were proportionally rated as satisfactory rather than dissatisfactory include:

- $\quad$ Q9. Waterside Landscapes (55.8\%)

- Q4. Enjoyment of Tea Houses (53.9\%).

That is to say, tourists were most impressed with perfect infrastructure (especially sanitation), the preservation of historical buildings, natural landscapes and traditional street landscapes (Overall Atmosphere). They enjoyed time spent with family and friends, traditional delicacies as well as leisure and rest. Visits to ancient towns are predominantly aimed at viewing traditional buildings, and thus the satisfaction for this category is relatively high. In addition, satisfaction with conditions of cleanliness and hygiene, nature, and space is considerably high.

On the other hand, those elements which were hardly rated as satisfactory or fairly satisfactory (below $40 \%$ ) were:

- $\quad$ Q2. Verbal Introduction to Traditional Life (36\%)

- $\quad$ Q5. Communication with Local Residents (34.5\%)

- $\quad$ Q3. Experience of Local Traditional Life (25.3\%).

Table 2. Proportion of Tourist Satisfaction.

\begin{tabular}{lcc}
\hline \multicolumn{1}{c}{ Tour Elements } & Rating & Satisfaction (\%) \\
\hline Q1. Enjoyment of Local Life & $\bullet$ & 45.7 \\
Q2. Verbal Introduction to Traditional Life & $\bullet$ & 36 \\
Q3. Experience of Local Traditional Life & $\bullet$ & 25.3 \\
Q4. Enjoyment of Tea Houses & $\bullet$ & 53.9 \\
Q5. Communication with Local Residents & $\bullet$ & 34.5 \\
Q6. Enjoyment of the Sichuan Opera & $\bullet$ & 31.2 \\
Q7. Historical Buildings & $\bullet$ & 67.9 \\
Q8. Traditional Street Landscapes (Overall Atmosphere) & $\square$ & 71.6 \\
Q9. Waterside Landscapes & $\square$ & 55.8 \\
Q10. Green Vegetative Landscapes & $\bullet$ & 62 \\
Q11. Historical Anecdotes & $\bullet$ & 41.1 \\
Q12. Education on Local History and Culture & $\bullet$ & 49.7 \\
Q13. Enjoyment of Traditional Delicacies & $\times$ & 70.1 \\
Q14. Enjoyment of Non-Traditional Foods & $\bullet$ & 42.2 \\
Q15. Availability of Traditional Objects for Sale & $\times$ & 39.8 \\
Q16. Availability of Non-Traditional Items for Sale & $\times$ & 29.2 \\
Q17. Leisure and Rest & $\times$ & 68.1 \\
Q18. Enjoyment of Mahjong & $\times$ & 31 \\
Q19. Reunion of Family and Friends & $\times$ & 63.3 \\
Q20. Encounter & $\square$ & 20.7 \\
Q21. Street Cleanliness & $\square$ & 73.9 \\
Q22. Bathroom Cleanliness & $\square$ & 68.6 \\
Q23. Street Comfort & $\square$ & 79.3 \\
Q24. Enjoyment of Rest Stops & $\square$ & 65.9 \\
Q25. Commentary on Streets & $\square$ & 39.6 \\
Q26. Enjoyment of Night Life & $\square 5.7$ \\
\hline
\end{tabular}




\section{Analysis Based on CS}

ANOVA was conducted before a CS analysis in order to establish whether these five areas can be analyzed holistically, rather than individually. In other words, to ensure that there are obvious differences between all factors and areas. Inspection level $\alpha=0.05$, and except for four of the factors, which are (Q7. Historical Buildings), (Q9. Waterside Landscapes), (Q17. Leisure and Rest) and (Q23. Street Comfort), which have obvious differences, there is no difference among the remaining 22 factors and areas. Therefore, it is believed that the five areas can be investigated as a whole.

\subsection{About CS Analysis}

The CS analysis method is widely used in the market field. Importantly, the method suggests key improvement areas through the analysis of the relationship between the satisfaction degree of each element and the comprehensive satisfaction degree of the entire site. In this research, the five-segment rating method is applied to analyze comprehensive satisfaction: (Are you satisfied with "OO"? where "OO" represents the tourism site).

The analysis procedure of the CS method is as follows [26,27]:

(1) In order to measure tourist satisfaction in various tourism projects, the five-segment rating method is quantified (as detailed in Section 5) to calculate the deviation value. This value is defined as the degree of deviation of satisfaction: the higher the degree of satisfaction, the greater the deviation.

(2) In order to measure the importance of the element in the tourist site, the correlated coefficient of each tourism site's comprehensive satisfaction is calculated and transformed into a deviation value, which is called the deviation value of importance degree. The deviation value of importance degree stands for the degree of comprehensive influence. (The details of the calculation are presented in the complementary file).

(3) The vertical axis represents the deviation value of the satisfaction degree, while the horizontal axis represents the deviation value of the importance degree. The various elements are converted into a planar graph, namely the CS graph generation (Figure 1).

(4) The order of improvement is called the improvement degree. The calculation method is as follows:

a. calculate the distance of each index point $\mathrm{O}(50,50)$

b. draw a line from point $\mathrm{O}$ to the lower right corner $(80,20)$

c. calculate the angle of each index point $(x, y)$ and the origin of the straight line, with a straight line (the distance from the origin point to the lower right corner of the line 80,20)

d. the angle is called $\alpha$, according to the following formula to calculate the correction index $\gamma$ :

$$
\gamma=\left(90^{\circ}-\alpha\right) / 90
$$

The negative index is negative when the priority is low.

The higher the priority quadrant, the smaller the angle, the greater the correction index.

(5) determination of the distance between the intersection point of the $X$ and $Y$ axes $(50,50)$ to each project location:

$$
\text { Distance }=\sqrt{(x-50)^{2}+(y-50)^{2}}
$$

(6) Calculation of the improvement index: the distance from the coordinate point $\mathrm{O}$ is multiplied by the correction index $\rightarrow \mathrm{L} \times \gamma$

The improvement index value $=$ distance $\times$ correction index 
When the index is positive, the greater the value, and the higher the degree of improvement priority. When the index is negative, there is no need for improvement, only maintenance.As shown in Figure 1, the graph is divided into four quadrants, each of which is closely related to the comprehensive satisfaction. The quadrant labelled "focused improving field" demarcates where a low degree of satisfaction is closely related to the comprehensive satisfaction. On the other hand, the correlation in "focused maintenance field" between a high degree of satisfaction and the comprehensive satisfaction is relatively weak, but "focused maintenance field" with a high degree of satisfaction is weakly correlated with the comprehensive satisfaction while lower satisfaction "improving field" is not.

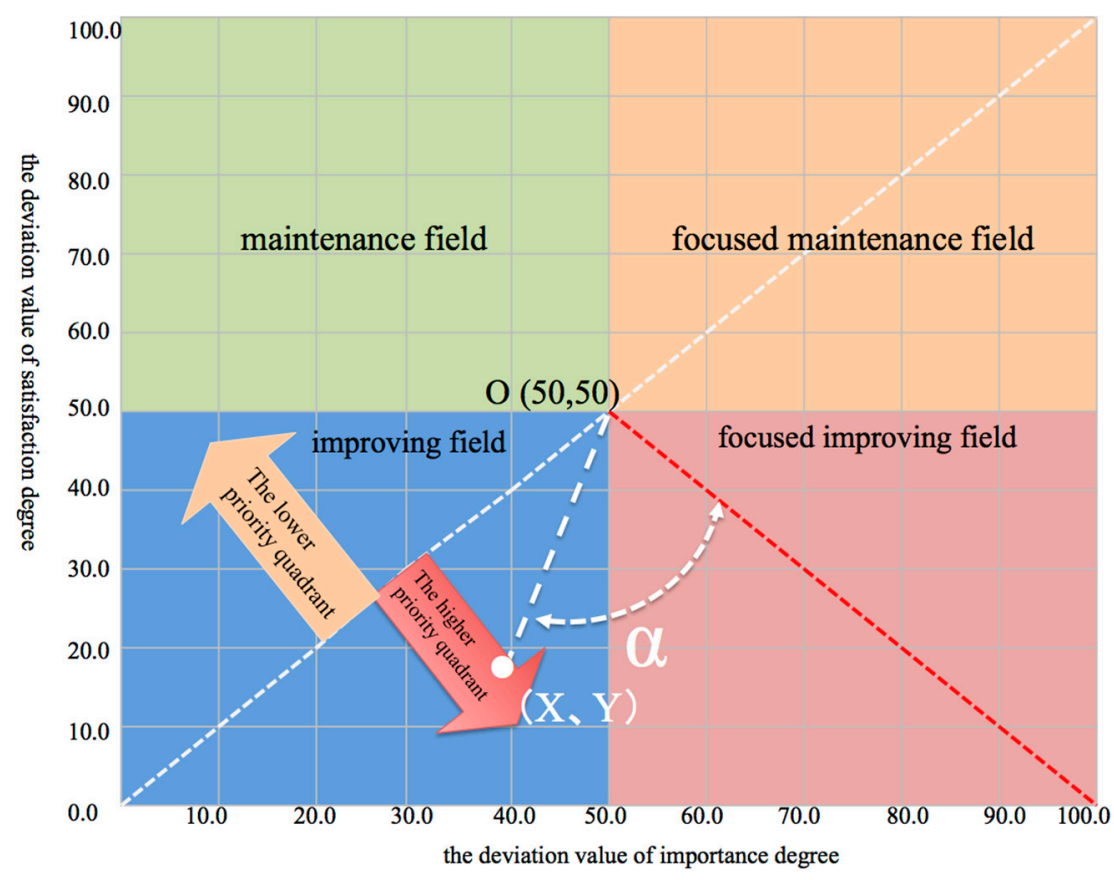

Figure 1. Concept Map of CS Graph.

\subsection{Analysis of Traditional Tourism Site Based on the CS Analysis Method}

CS analysis can be used to establish the advantages and disadvantages of tourism resources and to provide an objective basis for relevant tourism development policies. The results are shown in Figure 2 and Table 3.

In the current situation, the advantageous resources of the tourism sites studied and resources to maintain in future are distributed in the second and third quadrants, respectively.

The second quadrant demarcates the "focused maintenance field". These elements-as key elements of importance-are the origin of tourist satisfaction. This quadrant consists of street landscapes, historic buildings and other architectural landscapes, waterfronts, green landscapes and other natural landscapes, street and bathroom cleanliness as well as leisure and rest places, and traditional delicacies. It can be seen from these elements that satisfaction of tourists with respect to traditional areas is concerned with landscape elements (historic districts, natural landscapes), infrastructure (clean space, rest places) and visible resources such as traditional delicacies.

The third quadrant is the "maintenance field" of current elements. "Street Comfort" "Reunion of Family and Friends" and "Enjoyment of Tea Houses" appear here. Tourists are not particularly aware of the importance and necessity of these elements, but they are essential elements of tourism. Therefore, the tourism elements of the third quadrant only require continued maintenance and no improvement at this stage. 


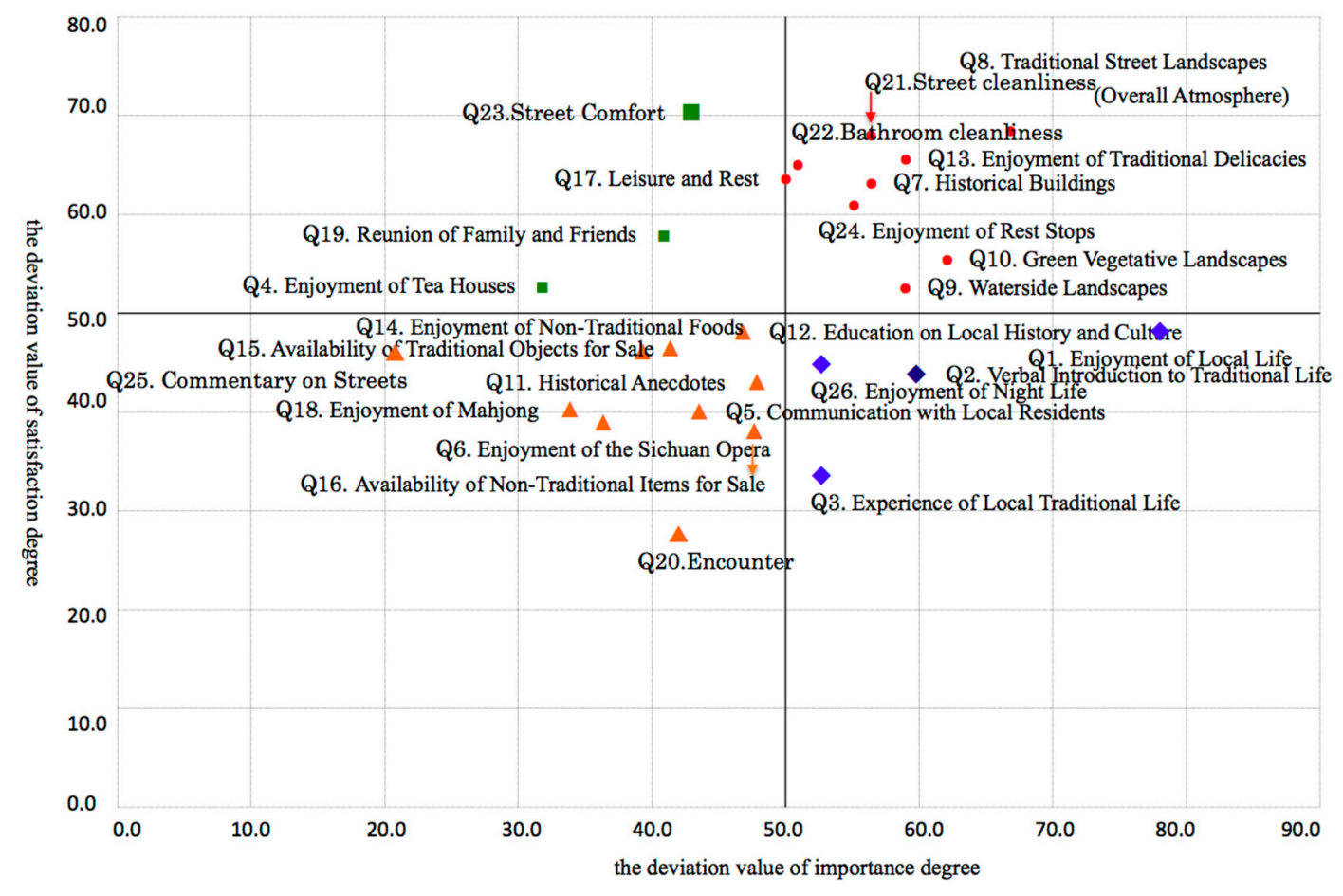

Figure 2. CS-Portfolio-Based Overall Analysis of Regions.

The elements in the "focused maintenance field" (hereinafter designated by $\star$ ) are roughly the same as the 12 elements with a high satisfaction degree as established in Section 5. On this basis, eight additional elements need to be included in the following list, namely:

- $\quad$ Street Comfort $(79.3 \%)$

- $\quad$ Street Cleanliness $(73.9 \%)$

- $\quad$ Bathroom Cleanliness (68.6\%)

- $\quad$ Traditional Street Landscapes (Overall Atmosphere) (71.6\%)

- $\quad$ Historical Buildings $(67.9 \%)$

- $\quad$ Enjoyment of Rest Stops (65.9\%)

- $\quad$ Green Vegetative Landscapes (62\%)

- $\quad$ Waterside Landscapes (55.8\%).

It can be seen that what dominates here is the quality of the environment and sanitation infrastructure. The regional resources that are in need of maintenance, but not a priority, are:

- $\quad$ Enjoyment of Traditional Delicacies (70.1\%)

- $\quad$ Leisure and Rest (68.1\%)

- $\quad$ Reunion of Friends and Family (63.3\%)

- $\quad$ Enjoyment of Tea Houses (53.9\%).

On the other hand, the low degree of satisfaction-with respect to the current situation, the region's inferior resources-need to be promoted in order to improve the overall satisfaction of the elements in the first quadrant.

The first quadrant is the major field that requires improvement, with the distribution of elements in this quadrant prioritized. This quadrant focuses on:

- $\quad$ Enjoyment of Local Life (45.7\%)

- Verbal Introduction to Traditional Life (36\%) 
- $\quad$ Experience of Local Traditional Life (25.3\%)

- $\quad$ Enjoyment of the Night Life (45.7\%).

Among these four elements, there are three elements that are related to traditional cultural life. In addition, a series of intangible cultural resources on the comprehensive satisfaction degree are closely related to the improvement of the previous strengthening elements. However, "Enjoyment of Night Life" is different from the traditional elements: it is in high demand for tourists. Improvement of street lamps can enhance the comprehensive satisfaction of tourists but will affect the living environment of local residents. Therefore, exploration is required as to whether there is a need to consider the installation of street lights and how this might be integrated with the local residents' traditional cultural life.

The third quadrant shows disadvantageous resources that require improvement. However, the priority is relatively low: if there is an improvement of the elements in this quadrant, the comprehensive satisfaction of tourists will not be affected.

Table 3. The numerical value of the deviation value for the importance degree and the satisfaction degree.

\begin{tabular}{lcc}
\hline \multicolumn{1}{c}{ Tour Elements } & The Satisfaction Degree & The Importance Degree \\
\hline Q1. Enjoyment of Local Life & 47.16 & 77.61 \\
Q2. Verbal Introduction to Traditional Life & 41.37 & 60.72 \\
Q3. Experience of Local Traditional Life & 35.04 & 50.97 \\
Q4. Enjoyment of Tea Houses & 52.07 & 32.50 \\
Q5. Communication with Local Residents & 40.50 & 45.79 \\
Q6. Enjoyment of the Sichuan Opera & 38.53 & 36.46 \\
Q7. Historical Buildings & 60.36 & 54.54 \\
Q8. Traditional Street Landscapes (Overall Atmosphere) & 62.55 & 65.99 \\
Q9. Waterside Landscapes & 53.16 & 57.98 \\
Q10. Green Vegetative Landscapes & 56.87 & 61.92 \\
Q11. Historical Anecdotes & 44.43 & 49.26 \\
Q12. Education on Local History and Culture & 49.56 & 46.82 \\
Q13. Enjoyment of Traditional Delicacies & 61.67 & 57.82 \\
Q14. Enjoyment of Non-Traditional Foods & 45.08 & 44.01 \\
Q15. Availability of Traditional Objects for Sale & 43.66 & 40.78 \\
Q16. Availability of Non-Traditional Items for Sale & 37.36 & 48.85 \\
Q17. Leisure and Rest & 60.47 & 50.13 \\
Q18. Enjoyment of Mahjong & 38.42 & 34.18 \\
Q19. Reunion of Family and Friends & 57.64 & 42.59 \\
Q20. Encounter & 32.31 & 42.21 \\
Q21. Street Cleanliness & 63.97 & 56.10 \\
Q22. Bathroom Cleanliness & 60.80 & 50.97 \\
Q23. Street Comfort & 67.13 & 47.19 \\
Q24. Enjoyment of Rest Stops & 59.16 & 53.43 \\
Q25. Commentary on Streets & 43.55 & 39.43 \\
Q26. Enjoyment of Night Life & 47.16 & 51.76 \\
\hline
\end{tabular}

\subsection{Proposal}

Using the CS analysis method, we mapped the 26 elements of investigation onto four quadrants, calculated the importance of the various elements of tourism, and detailed which factors require improvement or maintenance. The greater degree of improvement required, the higher the priority. In this section, we analyse the elements with positive values. Key areas of improvement in the elements have been highlighted in gray in Table 4:

(1) The element with the highest degree of improvement, and thus priority, is "Enjoyment of Local Life (15.69)". The second is "Verbal Introduction to Traditional Life (12.82)". The third is "Experience of Local Traditional Life (8.11)". The fifth is the "Encounter (4.56)" and sixth is "Communication with Local Residents (2.44)". The seventh is "Historical Anecdotes (2.34)". The results show that the most important issue is that local residents are leaving the traditional areas. 
Tourism development has caused the loss of residents and, as a result, the daily life and culture of local residents has been dramatically imperiled and, possibly, even put at risk of extinction. This is reflected in the data on the elements that relate to the daily life of local residents, each of which is closely related to the residents of the area. Local residents are very important for protecting regional culture because they promote the inheritance of history and culture. Therefore, the key to preventing the loss of traditional culture is preventing the loss of local residents.

(2) The degree of improvement in "Enjoyment of Night Life (2.85: 8th)", "Green Vegetative Landscapes (2.30: 9th)", "Waterside Landscapes (2.23: 10th)" and "Traditional Street Landscapes (Overall Atmosphere) (1.55: 11th)" is relatively high. It is clear that the construction of the landscape is also important for tourism. The results show that the preservation of traditional scenery includes not only the preservation of buildings but also the green vegetative landscapes, natural landscapes and other elements of the landscape.

(3) The "Availability of Non-Traditional Items for Sale (5.61: 4th)" may be a blind spot in tourist demand. The pleasure of travel may be lost if there are no non-traditional items available for sale, resulting in people not realizing the pleasure of travel.

Table 4. The improvement of each element represents the order of priority improvement.

\begin{tabular}{lc}
\hline \multicolumn{1}{c}{ Tour Elements } & Improvement Degree \\
\hline Q1. Enjoyment of Local Life (1) & 15.69 \\
Q2. Verbal Introduction to Traditional Life (2) & 12.82 \\
Q3. Experience of Local Traditional Life (3) & 8.11 \\
Q4. Enjoyment of Tea Houses & -10.13 \\
Q5. Communication with Local Residents (7) & 2.44 \\
Q6. Enjoyment of the Sichuan Opera & -0.94 \\
Q7. Historical buildings & -2.69 \\
Q8. Traditional Street Landscapes (Overall Atmosphere) (11) & 1.55 \\
Q9. Waterside Landscapes (10) & 2.23 \\
Q10. Green Vegetative Landscapes (9) & 2.3 \\
Q11.Historical Anecdotes (8) & 2.34 \\
Q12. Education on Local History and Culture & -1.32 \\
Q13. Enjoyment of Traditional Delicacies & -1.74 \\
Q14. Enjoyment of Non-Traditional Foods & -0.48 \\
Q15. Availability of Traditional Items for Sale & -1.31 \\
Q16. Availability of Non-Traditional Items for Sale (4) & 5.61 \\
Q17. Enjoyment of Leisure and Rest & -5.16 \\
Q18. Enjoyment of Mahjong & -1.92 \\
Q19. Reunion of Family and Friends & -10.54 \\
Q20. Encounter (5) & 4.56 \\
Q21. Street Cleanliness & -3.62 \\
Q22. Bathroom Cleanliness & -4.81 \\
Q23. Street Comfort & -10.48 \\
Q24. Enjoyment of Rest Stops & -2.66 \\
Q25. Commentary on Streets & -1.87 \\
Q26. Enjoyment of Night Life (6) & 2.85 \\
\hline
\end{tabular}




\section{Conclusions}

This study takes tourist sites in Chengdu and its surrounding areas as a case study and makes use of the CS analysis method to establish key elements in the sustainable development of traditional tourism, which, as a result, may develop resources for tourism policies. Conclusions can be drawn as follows:

(1) In traditional areas, "Traditional Street Landscapes (overall atmosphere)", "Historic Buildings", "Waterside Landscapes" and "Green Vegetative Landscapes" and similar tangible resources are the primary elements of tourists' satisfaction. In contrast, the satisfaction of "Enjoyment of Local Life", "Verbal Introduction to Traditional Life" and "Experience of Local Traditional Life" is relatively low in the current situation, but most closely related to the comprehensive satisfaction. Thus, an improvement of these elements will be most effective to improve the comprehensive satisfaction degree. In addition, a certain degree of customer satisfaction was also achieved in relation to street comfort, cleanliness of roads and bathrooms, and other infrastructure. However, it can be seen that tourist satisfaction lies not only in infrastructure, historical buildings, natural environments and other tangible resources but is also closely related to intangible heritage such as history and culture, and the overall atmosphere. Therefore, what is fundamentally necessary is to help local residents understand tourists' desperate demands for local traditional cultural resources. In parallel, it will be important to inspire local residents to value and celebrate their traditional cultural lives and resources. The major question here will be how to effectively link traditional living and cultural resources with economic benefits because the improvement of the living conditions of local residents will be essential to encourage them to remain and subsequently improve the experience of tourists.

(2) This study discusses the subject of preventing the loss of local residents. How to keep local residents in their hometowns is closely linked to the government, traders, residents themselves and other aspects. Therefore, it is necessary to conduct studies on the basis of reality. In future research, it is necessary to study local government departments and recruit local residents as participants.

Overall, this research could play an important role in the revitalization of sustainable tourism in the future.

Acknowledgments: This work was supported by JSPS KAKENHI (Grant-in-Aid for Scientific Research (C)) Grant Number: P15K01941 and the Fundamental Research Funds for the Central Universities of China, Grant Number: JZ2016YYPY0065 and 2682014BR028.

Author Contributions: Then manuscript was primarily written by Yan Liu, with Shaowei Ning contributing to its preparation. Shaowei Ning, Li Li and Isao Oyama supervised the research and critically reviewed the draft.

Conflicts of Interest: The authors declare no conflict of interest.

\section{References}

1. Li, Y.B. Conception on Tourism Resources Protection and Development of East Sichuan Ancient Towns. In Proceedings of the 2012 International Conference on Social Science and Education, Xiamen, China, 27-28 December 2012; Volume 10, pp. 143-147.

2. Yan, Y.Y.; Zhang, L.R. A Comparative Research on Mechanism of “Community Participation" under Different Opearating Modes-Examples of ancient-village tourism. Hum. Geogr. 2008, 23, 89-94.

3. Wang, H.; Chen, Z.W.; Zhang, K. Research on the in uence Process of the Ancient Village Residents' Behavior to Psychological Carrying Capacity of Tourists. J. Cent. South Univ. For. Technol. Soc. Sci. 2014, 8, 1-5.

4. Zhang, B. A Study on the Tourism Destination Image of Hangzhou from the Cognitive Psychological View. Sci. Technol. West China 2012, 4, 75-77.

5. Chengdu Statistical Bulletin of National Economic and Social Development. 2001-2015. Available online: http:/ / www.tjcn.org (accessed on 10 August 2016). (In Chinese)

6. Wang, M.F. On conservation and maintenance of ancient buildings. Shanxi Archit. 2016, 42, 1-3. 
7. Song, T.; Zhou, J.M.; Cai, J.M.; Luo, X.X.; Li, B.; Song, Z.W. Domestic tourists' preference to Kashi City: China based on correspondence analysis. J. Arid Land Resour. Environ. 2013, 27, 173-178.

8. Liu, S.; Cui, X.L. An Empirical Analysis of Travel and Mental Health. J. Beijing Int. Stud. Univ. 2013, 11, $79-83$.

9. Zhang, B. A Research on Residents' Social-Psychological Carrying Capacity of Tourism Destinations: A Case Study on Asakusa Area Tokyo Japan. Tour. Trib. 2014, 29, 55-65.

10. Ma, C.; Zhang, G.; Su, Y. Research on the Strategies of Cultural Heritage in Villages and Towns Characterized by Aboriginal Participation. Urban Dev. Stud. 2013, 20, 37-41.

11. Han, L.A. The Tourist in China and Sustainable Tourism Prospects. Hum. Socio Environ. Stud. 2008, 3, 165-188.

12. Ling, M.H. World Heritages Pass on from Generation to Generation. J. Hubei Inst. Natl. Philos. Soc. Sci. 2004, 22, 16-21.

13. Qin, R. The tourism development of famous historical and cultural town. J. Leshan Teach. Coll. 2007, 22, $79-81$.

14. Yang, G.C. A Study of the Protection and Development of "Nuodeng" Village: A Bai Village of the Nanzhao Kingdom with a History of One Thousand Years. J. Yunnan Natl. Univ. Soc. Sci. 2002, 19, 67-74.

15. Zhang, D.T.; Qiu, F.D. A Summary of Ancient Town Tourism Studies at Home and Abroad. Tour. Trib. 2011, 26, 86-92.

16. Zheng, S.Q.; Wang, D.W. Research on Mode of Wuzhen Tourism Development. Areal Res. Dev. 2012, 31, 85-94.

17. Zhou, X.J.; Wu, X.L. On Ancient Town Tourist Resources Development. Knowl. Econ. 2008, 1, $131-132$.

18. Wang, Y.; Shi, C.Y. Research on Tourism Preference and Behavior of Rural Tourists in Suzhou City. Tour. Forum 2014, 7, 26-33.

19. Wang, Q.A.; Sun, G.N.; Tang, Y.Y. Empirical Analysis on Tourist Satisfaction and After-the-Tour Tendency of Traditional Scenic Spots A Case Study of Langya Mountain Scenic Spot. Resour. Dev. Market 2016, 32, $99-102$.

20. Long, Z.K.; Ren, H.D. Research on Tourist Satisfaction with Ancient City Based on Index Measuring Model: A Case Study of Phoenix Town. J. Shaoyang Univ. Soc. Sci. 2015, 5, 77-83.

21. Wang, J.W. Tourists' Perceptions of Negative Heritage lnterpretation in Natura1 Disaster Area-China: Case of the Beichuan Earthquakel Site Area in Sichuan Province. J. Jpn. Inst. Tour. Res. Tour. Stud. 2016, 27, 41-54.

22. Wang, J.W. Tourist Satisfaction in Negative Heritage Tourism in a Disaster-affected Area: The Case of the Beichuan Earthquake Site Area in Sichuan Province, China. J. Int. Media Commun. Tour. Stud. 2015, 20, 73-94.

23. Liu, Y.; Wan, K.; Li, L.; Simokawa, T.; Oyama, I. A study on Current Situation of Tourism Development in Chengdu and the Suburb Area-Investigation of Affecting Factors of Tourist for Traditional Tourism Area in China. Trans. Jpn. Soc. Kansei Eng. 2016, 15, 163-172.

24. Available online: http://baike.baidu.com/link?url=3V0ACqmKGJcyD35KVMF6QNRfv_ hNopprX8YxGbOWsP0IOpmGFEzCc7NsFBekoSv7TO03-oxA_aRLkuRsq63J1A0oJz0QxR1Qn2D0NL3QKte (accessed on 10 December 2016).

25. Yuksel, A.; Yuksel, F. Mea Measurement and management issues in customer satisfaction research: Review, critique and research agenda: Part one. J. Travel Tour. Market. 2011, 10, 47-80.

26. Miao, Q.; Arima, M.; Kawamukai, H. How to Use JMP in Revealing Issue Structure from a Questionnaire Survey in a Local Community. J. Socio Inform. 2009, 2, 3-18.

27. Fujiyosi, H.; Ushino, T.; Kuki, Y.; Hoshino, S. Grasping problems and analyzing trends of customers with customer satisfaction investigation in farmers markets. J. Rural Plan. 2007, 26, 329-334.

(C) 2017 by the authors. Licensee MDPI, Basel, Switzerland. This article is an open access article distributed under the terms and conditions of the Creative Commons Attribution (CC BY) license (http:/ / creativecommons.org/licenses/by/4.0/). 